\title{
Potential effects of Covid-19 on training in CAP: the balance after a year
}

\author{
Peter Deschamps ${ }^{1,2} \cdot$ Sue Bailey ${ }^{1,3} \cdot$ Bernadka Dubicka $^{4,5} \cdot$ Anna Sofie Hansen ${ }^{1,6}$. Johannes Hebebrand ${ }^{7,8}$. \\ Brian Jacobs ${ }^{1,9} \cdot$ Krisztina Kapornai $^{1,10}$. Paul Klauser ${ }^{7,11}$ • Hojka Gregoric Kumperscak ${ }^{1,12}$ - Alexis Revet ${ }^{7,13,14}$. \\ Asilay Seker $^{15,16} \cdot$ Carmen Schroder $^{1,17,18} \cdot$ Thorsten Schumann $^{1,19,20}$
}

Published online: 26 June 2021

(c) Springer-Verlag GmbH Germany, part of Springer Nature 2021

In January 2020 European Child + Adolescent Psychiatry (ECAP) devoted an editorial to the training of child and adolescent psychiatrists (CAPs) in the twenty-first century based on an analysis of the perceived challenges [5]. Little did we know that a worldwide crisis would set in shortly thereafter. Three months into the Covid-19 crisis, another ECAPeditorial reported on the first effects on child and adolescent mental health [4]. Training was expected to face a challenge in balancing between core clinical child and adolescent psychiatry (CAP) work and replacement of activities. Development of online training tools in national and international cooperation networks was expected and encouraged. Taking care of the mental health of our own workforce and sharing

Peter Deschamps

P.K.H.Deschamps@umcutrecht.nl

1 Section of Child and Adolescent Psychiatry, European Union of Medical Specialists (UEMS-CAP), Brussels, Belgium

2 Department of Psychiatry, University Medical Centre Utrecht, Utrecht, The Netherlands

3 Chair Centre for Mental Health, London, UK

4 University of Manchester, Manchester, UK

5 Pennine Care Foundation Trust, Ashton-under-Lyne, UK

6 Research Unit for Child and Adolescent Psychiatry, Aalborg University Hospital, Aalborg, Denmark

7 ESCAP Research Academy, Essen, Germany

8 Department of Child and Adolescent Psychiatry, Psychosomatics and Psychotherapy, University Hospital Essen (AöR), Wickenburgstr. 21, 45147 Essen, Germany

9 Child and Adolescent Psychiatry, South London and Maudsley Hospital, London, UK

10 Child and Adolescent Psychiatry Department, University of Szeged, Szeged, Hungary

11 Service of Child and Adolescent Psychiatry, Department of Psychiatry, Lausanne University Hospital, Lausanne, Switzerland strategies to monitor and strengthen mental health with other professionals was highlighted.

The sparse literature on the effects of the Covid pandemic on training psychiatrists and on CAP training in particular has reported anecdotally on changes in the areas of telemedicine, remote training and trainee wellbeing [20]. In an online survey, over a third of junior psychiatric trainees reported a major impact of lockdown with feelings of anxiety, loneliness, sadness, uncertainty, frustration and irritability [15]. Some have described creative solutions such as e-mentoring programs to continue support and preserve peer networks [7]. Others have reflected upon the effects of the pandemic on role-conflict of psychiatric residents. On the one hand

12 Child and Adolescent Psychiatry Unit, Department of Psychiatry, Faculty of Medicine, University Clinical Center Maribor, University of Maribor, Maribor, Slovenia

13 Service Universitaire de Psychiatrie de l'Enfant et de l'Adolescent, CHU de Toulouse, Toulouse, France

14 UMR 1027, Inserm, Université Toulouse III, Toulouse, France

15 Child and Adolescent Psychiatry Department, Erciyes University Hospital, Kayseri, Turkey

16 European Federation of Psychiatric Trainees, Brussels, Belgium

17 Department of Child and Adolescent Psychiatry, Strasbourg University Hospital, Strasbourg, France

18 Institute of Cellular and Integrative Neurosciences, CNRS UPR 3212, Strasbourg, France

19 Department of Child and Adolescent Psychiatry Southern Jutland, Hospital of Southern Jutland, Aabenraa, Denmark

20 University of Southern Denmark, Odense, Denmark 
they are still "trainees" and almost but not quite grown-ups; on the other, they have been expected during the crisis to behave more as "physicians" and full-grown specialist doctors [21].

This editorial assesses from an international perspective what we have learned together with our trainees about the direct and indirect effects of the Covid crisis including social distancing and school closure on training of our future generation of CAP. An online survey was conducted among 26 CAP trainers of the European Union of Medical Specialists (UEMS) section for CAP, the pan-European body responsible for advice on training. The survey was followed by a group discussion in an online round table meeting. To include the trainees' perspective, written feedback was collected via the European Federation of Psychiatry Trainees (EFPT) Annual Country Reports. This was further discussed with the EFPT member country trainees on several occasions, including the EFPT virtual sessions.

Overall patterns emerged in five domains relevant to and resonating with changes in training and education in CAP: a shift in the public view of mental health of young people; effects of social distancing on mental health; changes in health care services; direct effects on training and education; and last but not least, resilience and personal wellbeing.

\section{A shift in the public view of mental health in young people}

After an initial focus on somatic health and intensive care provision, the panel reported a trend towards more openness about the effects of school closure and social distancing measures on mental health reducing stigma. The importance of schooling became visible including teachers as role models, children's social development with friends and support of children living in adverse home situations. Awareness increased of the understanding that mental health is indeed a spectrum from wellbeing to frank illness and that we all share different vulnerabilities, resilience and ways of coping. This was encouraging for trainees and CAP staff; some even noted that our own children, friends and families developed a better understanding of the importance of our daily work.

In terms of advocacy, there were examples of new cooperation and joint efforts with parents and user organizations. Some of our young colleagues and trainees who were unfamiliar with the media and advocacy took their first steps on (social) media platforms. The voices of young people have also been picked up increasingly by the press, politicians and the general public. Arriving at solutions balancing the physical health of the elderly versus the mental health of young people has been difficult. Across the EU, roadmaps are being put together to plan for wellbeing and a positive influence on mental health in the future [9].

\section{Unequal effects of social distancing on mental health}

On the bright side, there were reports by the panel of phases in the lockdown where trainees, staff as well as some of the parents seeking help seemed to spend more quality time together with their children in their homes, away from other social obligations. However, many parents and caretakers experienced increased stress at home juggling work and their children's educational needs. This is in line with a study that showed that some parents report an increase in stress at home, while others describe positive effects [23] and the UK Co-SPACE study illustrating parents trying to balance their work and child-care commitments [17].

Most concerning to both CAP trainers and trainees were reports of increased inequality as the effect of school-closures was found to be most severe in those from lower income families. In England, a prevalence survey confirmed that children and young people living in households experiencing financial or food insecurity were also more likely to have a mental health condition [25],the financial insecurity experienced by many families during the pandemic has further exacerbated any pre-existing inequalities [10].

\section{Changes in health care services}

We saw an increase in cooperation with other mental health, school and community workers using video-conferencing tools. Better collaboration emerged between departments of CAP to register emergencies as well as a better liaison with pediatricians. Worrying reports came from countries regarding an initial drop in availability of CAMHS and some trainees and staff were reassigned to COVID treatment facilities. These reports are in line with the results from a survey of the Research Academy (RA) of the European Society of Child and Adolescent Psychiatry (ESCAP) that encourages the dual formation as clinician-scientist among CAP trainees [19]. The CovCAP study assessed, among 168 heads of CAP services in 24 European countries, their subjective perception of the first effects of the pandemic [18]. Eighty percent of the CAP services reported a major effect on service provision. The numbers of outpatients on average fell by two thirds and inpatients by one third. There was also a moderate to severe reduction in contact of professionals with parents and carers $(40 \%)$ and the transformation or closing of a part of the service for emergency COVID-19 use (59\%). Based on the reports of the panel of the current study, 
this was followed by an increase later in time in demand on CAP services placing a significant burden on already over-stretched staff and trainees. Our panel input suggests that as a result of all this, some trainees fell behind in previously set learning goals for their already limited period of training. Although it could be argued that some trainees learned new perspectives and skills working in emergency departments, the EFPT received reports of lack of training on acute somatic management of Covid-19 patients and of mental aspects of "long" covid, increasing stress and insecurity among trainees.

A rise in online health provision was often accompanied by initial problems with privacy and IT support of online health provision and telemedicine. Digital health interventions are promising therapeutic interventions for children and adolescents with psychiatric disorders. SARS-CoV2-19 has catalyzed the integration of these approaches into the standard repertoire of CAP; there are still challenges to overcome [1]. Of special interest to trainees, learning of how to build a treatment alliance, crucial in CAP for good quality of assessment and shared-decision making, was found to be more difficult and tiring using tele-medicine. The CovCAP study also reported a rapid adoption of telemedicine by $95 \%$ of services, despite its sparse use before the pandemic (20\%) and the absence of guidelines to accompany these changes [18].

\section{Direct effects on training and education}

The panel of trainers and trainees saw an increase in employment of online tools. This led to increased democratization of information for CAP trainees working in more remote or deprived areas providing greater access to training through the increasing use of digital training activities. Improved knowledge of platforms and easier accessibility proved fruitful for working in national and international networks. Cooperation to produce training modules online and blended learning has increased.

According to the feedback received by the EFPT, in multiple EU countries the replacement of face-to-face training and in-person academic conferences with online sessions has sometimes led to a reduction in the quality of training. Group-learning and support, often crucial for reflection of trainees, were jeopardized. These reports seem to be in step with a study among psychiatric trainees and faculty who perceived in-person learning more favorably than remote learning across a variety of domains, including enjoyment, connection and concentration. The experience has challenged the idea that all teaching has to be in person. Only $10 \%$ of trainees and $14 \%$ of faculty felt that all lectures would be most effectively delivered in-person in the future [13].
Exposure to research training in CAP was jeopardized. It became more difficult as many clinical studies were put on hold and trainees had to prioritize the consequences of the pandemic. A recent contribution mentioned positive effects of increased reflection and technology-aided cooperation as well as additional problems for trainees including the temporary suspension of all grant applications by different funding agencies, inability to obtain work and study permits for international exchange programs because of the closure of government facilities and closure of laboratory facilities [12].

\section{Resilience and the personal wellbeing of CAP staff}

Based on the reports from both trainers and trainees, a combination of the changes mentioned above led to an increase in work-related stress jeopardizing the mental health of at least some part of the CAP workforce. It potentially increased the risk of burnout, diminished the energy to engage in new projects or advocacy and may have negative effects on retention for trainees. This is in line with reports of child and youth mental health professionals experiencing problems with boundaries between work and their personal lives, satisfaction and feelings of inadequate practice as a result of an overnight transformation of in-person practice to virtual practice [3]. Specialty training was compared to the critical developmental years of a child; a period where investments for the future are made by gaining new skills, calibrating clinical perspectives, and building formative networks to potentially base future career advancements on. Adversity during training comes with the risk of producing less competent CAP specialists. and as a result of the aforementioned challenges some have also noted concerning signs of a decrease in recruitment to our specialty. It is too early to say if this is a real trend or not.

To address the need of child and adolescent psychiatry trainees, reliable, basic information about any changes affecting their training is highly important [16]. Providing wellbeing activities, case-discussion groups or individual support was found to help trainees deal with adverse experiences due to changes in their training and working conditions. Educators need to consider the timely adjustment of the curriculum to integrate remote teaching and learning opportunities. The Covid crisis seems to have taught both trainers and trainees a great deal about positive psychology and its importance in supporting resilience. It has also shown the importance of the hidden curriculum we are providing to our trainees [20]. By role-modeling our ability to cope with uncertainty, we provide lessons that will shape trainees' leadership styles and guide whole system interventions in a much more coherent way. 


\section{Conclusion}

The CAP trainees of today will become CAP specialists of tomorrow and should be equipped to tackle the workload and severity of mental health problems of children and young people during and after the pandemic. The key should be to develop novel solutions. How can we take advantage from adversity to look at how we can improve training in CAP and the effects it has on mental health care in the future? We have learned that it remains crucial to optimize the changing circumstances for CAP training, particularly by facilitating an effective digital shift in education and clinical work, cooperating in digital networks and supporting the personal well-being of trainees. We have found new allies in our pursuit to improve mental health. Across the EU, we have had common core experiences in terms of flexing our service delivery, whether driven by our own best decisions as clinicians or having to fit in with what was seen by most countries as the higher order necessity of COVID physical healthcare.

We know there will be long-term consequences of the pandemic for infants, children and young people as well as for our trainees learning how to deal with the challenges of our profession. Stains of what young people experience today will have an effect in the future and our trainees are no exception to the fact that we just do not yet know what these effects will be. Some will come out stronger. The vulnerable are more likely to be pushed closer to (the brim of) decompensation. Something will have been gained for trainees as well as trainers, even if that were limited to learning about their own personal resilience.

Training in (child) psychiatry seems to be no exception. Training directors all over medicine have become more concerned with protection of their trainees and their education [20]. The challenges seem to have been similar: providing proper training in the face of a huge burden with a dramatically changed clinical and administrative workload due to the pandemic. Based on international publications the pandemic affected many medical specialty training programs (e.g.: [2, 6, 14, 24]; see: [11].

We acknowledge a positive momentum with increased societal awareness of mental health of children and young people for the future. Reasons we matter as child psychiatrists have become more explicit. What we have to offer to society and the rest of medicine and why high-quality care and training and education in CAP matters has become clearer. General awareness of the plain fact that there can be no health without mental health is crucial for the willingness to invest in resources that are needed. We need parity between mental and physical health, and society needs to take this opportunity to build back better and fairer, addressing inequalities including the racial divides that have been exposed by Covid-19 [8], as well as an emphasis on young people's input in designing services and their values [22].

There is now a window of opportunity to increase the evidence we have on the impacts of development and the environment on mental health and to provide our trainees with the skills to learn from public health medicine to influence social policies. An important lesson that trainees can take into their future may be that external threats can lead to breaking down barriers, increasing collaboration and that a crisis is never to let go unused and always an opportunity to learn new lessons and skills.

\section{References}

1. Allgaier K, Schmid J, Hollmann K, Reusch PA, Conzelmann A, Renner TJ (2020) Times are changing: digitalisation in child and adolescent psychotherapy. Eur Child Adolesc Psychiatry. https://doi.org/10.1007/s00787-020-01610-8 (PMID: 32737600; PMCID: PMC7393619)

2. Cravero AL, Kim NJ, Feld LD, Berry K, Rabiee A, Bazarbashi N, Bassin S, Lee TH, Moon AM, Qi X, Liang PS, Aby ES, Khan MQ, Young KJ, Patel A, Wijarnpreecha K, Kobeissy A, Hashim A, Houser A, Ioannou GN (2020) Impact of exposure to patients with COVID-19 on residents and fellows: an international survey of 1420 trainees. Postgrad Med J. https://doi.org/10.1136/postg radmedj-2020-138789

3. Chrisman AK (2020) Debate: \#Together despite the distance. Child Adolesc Mental Health 25(3):180-181. https://doi.org/10. 1111/camh.12406

4. Clemens V, Deschamps P, Fegert JM, Anagnostopoulos D, Bailey S, Doyle M et al (2020) Potential effects of "social" distancing measures and school lockdown on child and adolescent mental health. Eur Child Adolesc Psychiatry 29(6):739-742. https://doi. org/10.1007/s00787-020-01549-w

5. Deschamps P, Hebebrand J, Jacobs B, Robertson P, Anagnostopoulos DC, Banaschewski T, Birkle SM, Dubicka B, Falissard B, Giannopoulou I, Hoekstra PJ, Kaess M, Kapornai K, Klauser P, Revet A, Schröder CM, Seitz J, Şeker A, Signorini G (2020) Training for child and adolescent psychiatry in the twenty-first century. Eur Child Adolesc Psychiatry 29(1):3-9. https://doi. org/10.1007/s00787-019-01467-6 (PMID: 31950371;PMCID: PMC6987048)

6. Edigin E, Eseaton PO, Shaka H, Ojemolon PE, Asemota IR, Akuna E (2020) Impact of COVID-19 pandemic on medical postgraduate training in the United States. Med Educ Online 25(1):1774318. https://doi.org/10.1080/10872981.2020.1774318

7. Ercan ES, Tufan AE, Kütük ÖM, Yazıcı İP (2021) E-mentoring program organized by the Turkish Association for Child and Adolescent Psychiatry during the COVID-19 pandemic. Eur Child Adolesc Psychiatry 30(1):173-175. https://doi.org/10.1007/ s00787-020-01671-9

8. Farquharson WH, Thornton CJ (2020) Debate: Exposing the most serious infirmity-racism's impact on health in the era of COVID19. Child Adolesc Mental Health 25:182-183

9. Fegert JM, Kehoe LA, Çuhadaroglu Çetin F, Doyle M, Eliez S, Hebebrand J et al (2021) Next generation Europe: a recovery plan for children, adolescents and their families: for the time after the pandemic, we need a vision and investments for the future. Eur Child Adolesc Psychiatry. https://doi.org/10.1007/ s00787-021-01767-w 
10. Ford T, John A, Gunnell D (2021) Mental health of children and young people during pandemic. BMJ (Clinical Research Ed) 372:n614. https://doi.org/10.1136/bmj.n614

11. Giordano L, Cipollaro L, Migliorini F, Maffulli N (2020) Impact of Covid-19 on undergraduate and residency training. Surgeon. https://doi.org/10.1016/j.surge.2020.09.014

12. Gnanavel S, Orri M, Mohammed M, Dray J et al (2020) Child and adolescent psychiatry research during the COVID-19 pandemic. Lancet. https://doi.org/10.1016/S2215-0366(20)30314-X

13. Heldt JP, Agrawal A, Loeb R, Richards MC, Castillo EG, DeBonis K (2021) We're not sure we like it but we still want more: trainee and faculty perceptions of remote learning during the COVID-19 pandemic. Acad Psychiatry. https://doi.org/10. 1007/s40596-021-01403-4

14. Imran N, Masood H, Ayub M, Gondal KM (2020) Psychological impact of COVID-19 pandemic on postgraduate trainees: a crosssectional survey. Postgrad Med J. https://doi.org/10.1136/postg radmedj-2020-138364

15. Nanjundaswamy MH, Pathak H, Chaturvedi SK (2020) Perceived stress and anxiety during COVID-19 among psychiatry trainees. Asian J Psychiatr 54:102282. https://doi.org/10.1016/j.ajp.2020. 102282

16. Ojha R, Richards M (2020) Child psychiatry training during COVID-19: impact on clinical care, education, and fellow wellbeing. JAACAP Connect Special Issue: The Covid-19 Pandemic

17. Raw J, Waite P, Pearcey S, Creswell C, Shum A, Patalay P (2021) Examining changes in parent-reported child and adolescent mental health throughout the UK's first COVID-19 national lockdown. https://www.psych.ox.ac.uk/publications/1161569

18. Revet A, Hebebrand J, Anagnostopoulos D et al (2021) ESCAP CovCAP survey of heads of academic departments to assess the perceived initial (April/May 2020) impact of the COVID-19 pandemic on child and adolescent psychiatry services. Eur Child Adolesc Psychiatry. https://doi.org/10.1007/s00787-020-01699-x
19. Revet A, Hebebrand J, Bhide S et al (2018) Dual training as clinician-scientist in child and adolescent psychiatry: are we there yet? Eur Child Adolesc Psychiatry 27:263-265. https://doi.org/ 10.1007/s00787-017-1104-x

20. Richards M, DeBonis K (2020) Psychiatric training during a global pandemic: how COVID-19 has affected clinical care, teaching, and trainee well-being. Psychiatric Services (Washington, D.C.) 71(12):1300-1302. https://doi.org/10.1176/appi.ps.20200 0277

21. Shapiro MA (2020) Competence vs. identity, trainees vs. physicians: how COVID-19 has highlighted role confusion in residency training. Acad Psychiatry. https://doi.org/10.1007/ s40596-020-01346-2

22. Tan J, Fulford B (2020) Debate: COVID crisis, natural capital and clinical care-'building back better' for a new values-based CAMHS. Child Adolesc Mental Health 25:184-186

23. Thorell LB, Skoglund C, de la Peña AG, Baeyens D, Fuermaier ABM, Groom MJ et al (2021) Parental experiences of homeschooling during the COVID-19 pandemic: differences between seven European countries and between children with and without mental health conditions. Eur Child Adolesc Psychiatry. https:// doi.org/10.1007/s00787-020-01706-1

24. Veerasuri S, Vekeria M, Davies SE, Graham R, Rodrigues J (2020) Impact of COVID-19 on UK radiology training: a questionnaire study. Clin Radiol 75(11):877.e7-877.e14. https://doi. org/10.1016/j.crad.2020.07.022

25. Vizard T, Sadler K, Ford,T, Newlove-Delgado T, Mcmanus S, Marcheselli F, Davis J, Williams T, Leach C, Mandalia D, Cartwight C (2020) Mental health of children and young people in England, 2020. Health and Social Care Information Centre. Available from: mhcyp_2020_rep.pdf (digital.nhs.uk) 